\title{
Letter to the Editor: Statements on the Contribution by Urbach et al. from Issue 4/2009
}

\section{DOI 10.1007/s12599-010-0096-6}

\author{
The Authors \\ Prof. Dr. Hans Ulrich Buhl ( $\varangle)$ \\ FIM Research Center Finance \& \\ Information Management \\ University of Augsburg \\ Universitätsstraße 12 \\ 86159 Augsburg \\ Germany \\ hans-ulrich.buhl@wiwi.uni- \\ augsburg.de
}

Prof. em. Dr. Dr. h.c. mult. Peter Mertens

Prof. Dr. Matthias Schumann

Dipl.-Wirt.-Inf. Nils Urbach

Prof. Dr. Stefan Smolnik

Prof. Dr. Gerold Riempp

Published online: 2010-03-10

This article is also available in German in print and via http://www. wirtschaftsinformatik.de: Buhl $\mathrm{HU}$, Mertens P, Schumann M, Urbach N, Smolnik S, Riempp G (2010) Leserbrief: Stellungnahme zum Beitrag von Urbach et al. aus Heft 4/2009. WIRTSCHAFTSINFORMATIK. doi: 10. 1007/s11576-010-0217-3.

(C) Gabler Verlag 2010

\section{Section BISE - Discussion}

In the section BISE - Discussion you usually find discussions of several distinguished experts on important and topical issues of the field. In addition, the section offers the possibility to publish letters to the editor (e.g., on recently published contributions), thereby promoting the scientific discourse.

The following is a statement by the colleagues Peter Mertens and Matthias Schumann on the contribution "The State of Research on Information Systems Success - A Review of Existing Multidimensional Approaches" by Urbach et al. (2009b), which appeared in issue 4/2009 in the section BISE - State of the Art, and subsequent comments by the authors.
The authors of the critical statement primarily focus on the question of which benefits result from the working results of researchers in business and information systems engineering (BISE) for economy and society. This fundamental issue certainly requires further discussion within the BISE community, which we intend to trigger by the presentation of the following two positions.

If you would like to comment on this topic or another article of the journal Business \& Information Systems Engineering (BISE), please send your contribution (max. 2 pages) to hansulrich.buhl@wiwi.uni-augsburg.de.

\section{Prof. Dr. Hans Ulrich Buhl Editor-in-chief}

\section{Comments on the Contribution by Urbach et al. "The State of Research on Information Systems Success - A Review of Existing Multidimensional Approaches"}

The contribution published in the section State of the Art invites some general, critical remarks about the methods used and the contents presented.

\subsection{On purpose and Precision}

The authors have set themselves the task of surveying the state-of-the-art in the field of measuring the success of information systems. This requires a definition of the success measure. Information systems as an instrument of company management in market economies have to if we want to determine their success focus on the primary goal in the theory of the firm, which is to maximize the profitability in its various forms (maximize the return on equity, the return on assets, the shareholder value, the sustainable enterprise value). As far as ceteris paribus clauses can be justified, this may be limited to sub-goals, such as revenue maximization, cost minimization, profitability-maximizing cycle time optimization. If the legitimacy of such clauses is not necessarily apparent from the context, the limitation has to be argued by the researcher.

In this case, the authors provide a definition based on DeLone and McLean according to Fig. 1. This happens after the authors have given an overview of U.S. research on "IS success", reaching up to a publication of Mason from 1978 (missing in the references) and one by Keen from 1980. Accordingly, six "dimensions of IS success can be distinguished" (p. 316). Only the "organizational impact", which is however not explained in detail by Urbach et al., can - as a concession - be classified as a major success in terms of the theory of the firm. In addition, success measures are mentioned such as "completion of a system on time and under budget", which are probably more typical for the controlling of a development project than for making statements about IS success as such. Let us illustrate the difficulty of DeLone and McLean's definition by a deliberately dramatic example: Suppose a car manufacturer may provide an individual employee portal for each of its approx. 100,000 staff members and even extend it by some gadgetry. The portal would be most widely used and the user satisfaction in terms of the presented model would be high. The efforts to develop, implement, run, and maintain the portal are not acceptable from a corporate point of view. In the view of Urbach et al. or of their U.S. models, however, the system would be a great success.

Conflicting objectives, which should cause many worries for the system architects and which should be analyzed by the business and information systems engineering (BISE) discipline, are not discussed by Urbach et al. Consider, for example, the development of systems which require much user effort in terms of training and time on the customer's side (vulgo: frustration tolerance), but which pursue a corporate goal (e.g., maximization of profitability in preparation for an IPO with - in the provider's view inexpensive but software-ergonomically unacceptable ticket machines of the Deutsche Bahn AG).

Medium- and short-term interim goals of a company may be situational. Thus, 
in a depression one tends to deliver remaining orders very punctually, whereas at the peak of an economic cycle it is more important to utilize the maximum capacity. The success of an IT system can also be measured with regard to the extent to which it permits such adjustments or what opportunities it offers also to not extremely specialized system administrators to allow for the current measure of success through parameter (re)configuration. Particularly in this case, the contribution of the well-trained BISE specialist for the prosperity of the company becomes apparent. According to our knowledge, such sophisticated reflections cannot be found in the U.S. literature, and thus in the works Urbach et al. refer to. However, the intense study of the German-language BISE literature would have yielded some relevant studies.

If the net benefits characterize the success of a system, then it is most likely determined by the gross benefits minus costs that are necessary for developing and running the system. Costs, however, are not considered by the authors in the presented approach.

Already in 1981, we can find publications in the U.S. literature on the effectiveness of the use of IS, distinguishing clearly between the efficiency of system development and system operation as well as the effectiveness of system usage in order to consolidate these for the overall IS assessment (Hamilton and Chervany 1981).

A closer analysis of the work by DeLone and McLean, especially of the original contribution from the year 1992, reveals that primarily examples from the class of Management Information Systems and Decision Support Systems are mentioned (DeLone and McLean 1992). The authors construct a meta-model to characterize the effects of such solutions on decision makers and the effects on their behavior, influenced by the systems, on the organization. This explains, for example, that higher user satisfaction and acceptance leads to greater influence on management decisions (individual influence). The success of a system which is used to automate a task that was previously handled manually cannot be assessed directly with this scheme. Here, we have to determine the influencing factors of the model that are of any relevance to this problem at all and how the specific effects can be measured. In their contribution from 2003, DeLone and McLean show the development of a list of criteria for e-commerce applications (DeLone and McLean 2003). This is done, however, without actually operationalizing it by an example and examining its practical suitability.

Thus, the model of DeLone and McLean focuses less on the actual measurement of a success than on the demonstration of interactions between different factors that have particular influence on decision making in companies.

With regard to the designated individual and organizational impact of IS, the German-language literature offers more comprehensive and finer distinctions, which are also backed up by extensive experience data for many examples on the basis of which generalizations can be derived (see next section).

Finally, at some points the contribution lacks linguistic precision as already becomes apparent from a logical error in the title (can we also analyze an approach that does not exist?).

\subsection{On Methodology}

The authors perform a literature study in line with the concerns of the section BISE - State of the Art. Although they use a lot of space for the description of their method of analysis, in some places the necessary self-criticism is missing. Thus, with the exception of the WIRTSCHAFTSINFORMATIK journal they limit their source selection exclusively to English-language journals and conference papers, with the excuse that "a field's major contributions are likely to be in leading journals [...] Books were deliberately omitted from the selection process on the assumption that their authors had already published their results in journals. Furthermore, the quality of the contributions is not always apparent, since not all of them were subjected to a formalized review process" (p. 317).

What a problematic logic: Doctoral theses and professorial dissertations, collected editions (exception: conference proceedings) are not worth considering because they do not undergo a formal evaluation process? The doctoral and professorial regulations of faculties around the world and not least in the German-speaking countries do not include an evaluation process? (Incidentally, many of them have decreed or are decreeing that essential parts of the examination paper may not be published in advance - even if you may be of divided opinions about the pros and cons of such rules.)

Another constraint of Urbach et al.'s study is the temporal limit, which is the publication period from 2003 to 2007 . In doing so, the authors discredited a large part of the German-language literature which has been compiled in a period when opponents of business information processing in Germany argued that this literature was extremely dangerous and should be prohibited or be subject to a moratorium. German BISE specialists in some cases significantly funded by the DP industry, headed by the former market leader IBM - conducted studies for which one can at least hardly deny an immense effort in detail, a methodology worth discussing in the form of building up a large database with all published quantitative and qualitative, positive and negative effects, as long as they were published directly from the day-today running of a business, and a workable reference framework (four-level model including an individual, business, economics, and world level; Mertens et al. 1982). Compare: DeLone and McLean mainly focus on the bottom level, the individual level. They would hardly be able to classify the global benefits of systems, such as for monitoring nuclear power plants, flight traffic, or even the global financial speculation. At the individual level of the four-level model we also do not have a focus on user acceptance. Instead, it is much more about gathering the benefits and costs of the systems at the individual workplace level.

Methodologically it is common in U.S. literature to examine productivity and profitability changes of economic sectors or economies with econometric studies or those of companies with microeconomic approaches. In this respect, the mentioned work of Brynjolfsson on the discussion of the productivity paradox gained special attention and resulted in many more empirical analyses on correspondingly aggregated databases (Brynjolfsson 1993). More recent studies, including those from the same author, now support the positive effect of IS investments at macro- and microeconomic level (e.g., Brynjolfsson and Hitt 2000; Pilat 2004). At the same time this also shows that while dealing with this topic, the objective and the object of the success measurement have to be clearly defined. Are we dealing with an economic 
examination or a precise investment decision or investment control? For the latter these forms of study provide no assistance. A differentiated examination based on the respective individual IS or the individual action is necessary.

In regard to the scope of analysis of the contribution (Fig. 2) we therefore have to critically scrutinize, for example, which data were collected in the surveys most commonly mentioned for data collection. Were they concerned with ordinally scaled characteristics or with querying and collecting quantified effects, thus is it about making judgments or determining facts?

Interestingly, in another study presented at the WI2009, in which one of the authors of the criticized paper was involved, quite different approaches to the "Benefits Management of IS/IT" have been presented than those considered here (Braun et al. 2009). Also this essay suffers - this is known from the presentation's discussion at the conference - from the choice and temporal limitation of the studied literature.

\subsection{Further Works on the Economic Success of Information Processing}

The following comments are intended to exemplarily indicate the extent to which the issue has also been addressed in German literature up to now.

In the journal WIRTSCHAFTSINFORMATIK we can at intervals, but repeatedly find "State of the Art" contributions on this subject and also research papers dealing with relevant sub-aspects. More recently, Walter and Spitta compare different evaluation approaches to assess effects of the IS use (Walter and Spitta 2004). In 2005, there is a contribution of Wehrmann and Zimmermann on the ex ante return and risk assessment of IT investments (Wehrmann and Zimmermann 2005). Based on this study there is a contribution which presents an approach to assess an entire IT project portfolio and also considers the interdependencies of the IT projects. For doing so, individual IT projects are positioned in a capital value/risk portfolio (Wehrmann et al. 2006). Leaving the temporal scope of the analysis set by the authors, Potthof collected and compared the results of empirical studies on the economic success of information processing in 1998 (Potthof 1998a, 1998b). In this work, there is also a typology that can be used to classify the various studies on the effects of information processing. Between the individual and company level, he additionally introduces the field level. Between the company level and economics level, he complements the sector level for effects of IP on industries or sectors. There is a table classifying further empirical work, also taken from German-language literature. In 1993, Schumann additionally presented and systematized approaches to assess the economic efficiency of IP systems (Schumann 1993).

Based on the previously mentioned work by Mertens et al., Anselstetter presents his dissertation on the economic efficiency of data processing in 1984 (Anselstetter 1984). He describes in detail the beneficial effects of data processing for individual functional areas of industrial and commercial organizations and credit institutions and develops models of how to estimate such calculations for specific applications ex-ante. The work is based on an extensive collection of individual cases in which the organizational results of a new or modified system use were reported.

In 1995, Linß particularly dwells on the effects of integration in information processing and tries to analyze the effects of different forms of integration of corporate systems through secondary research and case studies (Linß 1995).

Potthof continues these works in 1998 (Potthof 1998a). In his study, he investigates the effects of policy decisions, such as IP outsourcing, standard versus custom software, and distributed versus central information processing. In addition, he deals with workflow systems, data warehouse solutions, and sales systems. In the appendix of this work, there is a broad overview of studies analyzing the economic success of information processing on an empirical basis.

This shows that also German-speaking literature has a lot to offer in this field, not being limited to only general effect models, but also always claiming to provide support for real business decision situations.

\subsection{Outlook}

The paper by Urbach et al. deals with one of the main themes of IT or BISE in general, the "Cui bono?" It must therefore be examined very carefully. At the same time, it also offers an opportunity to discuss some present issues of BISE that have to be carefully considered in view of their distant effects.
1. Is it justified to mainly focus on the transfer of knowledge via research papers, and - what is more - limited to those from a few journals?

2. Is it required to adequately reflect the weaknesses of works from the U.S. sister discipline information system during their reception? In the overview paper by Urbach et al. some of these shortcomings become evident very clearly, such as the lack of connection of the IS with the theory of the firm, which are in turn often a result of the poor basic education of IS researchers in terms of business administration, the often observed distance from practical details, and the lacking overview due to the Americans' missing selfconfidence and their lack of language skills.

3. To what extent does truth count and to what extent are the year of publication, the language and the publication medium of significance?

A possibly separate, but referencing discussion of the work of Urbach et al. should not only refer to these issues, but also take into account on which paths, at what speed and to which cost (conference travel to Davos, Florida, Hawaii, Hong Kong, Madeira) the working results should reach which claimants. It should not be forgotten that this happens at the expense of the taxpayer as a principal beneficiary of working results from BISE in a world often referred to as a knowledge society.

Prof. em. Dr. Dr. h.c. mult. Peter Mertens Department of Information Systems I University of Erlangen-Nürnberg

Prof. Dr. Matthias Schumann Chair of Application Systems and E-Business University of Göttingen

\section{Statement of the Authors in Reply to the Comments by P. Mertens and M. Schumann on the Contribution "The State of Research on Information Systems Success - A Review of Existing Multidimensional Approaches"}

In terms of an active, stimulating, and sometimes controversial scientific culture of discourse, we thank Peter Mertens and 
Matthias Schumann for their comments on our article "The State of Research on Information Systems Success - A Review of Existing Multidimensional Approaches". Below we comment on these remarks. The structure of our argument is aligned to the structure of their letter to the editor.

\subsection{On Purpose and Precision}

The aim of our research paper was the analysis of publications in the field of measuring the success of information systems ("information systems success"), published in the period from 2004 to 2007 in leading journals and conference proceedings of the BISE or IS discipline. In our view, such a literature analysis requires not necessarily a definition of the success measure as this may vary significantly depending on the individual viewer and the objective of the investigation. In this context, success can be understood, for example, as a contribution to maximize profitability as postulated Mertens and Schumann. Just as well, it can be defined as satisfaction of the users of an information system (IS), to name just one alternative. To include as many facets of information system success as possible, we therefore did not formulate a restrictive definition for our literature analysis.

In fact, the "organizational impact" is deliberately not specified in detail in our paper. Nor do we take a detailed look at the success of other dimensions of success as specified by DeLone and McLean (2003). Background for this approach is that the presented model of success only serves as a framework for the multidimensional analysis of IS success. The operationalization of the different constructs/dimensions remains in the responsibility of the researcher himself. This of course also can - but must not - be made in terms of the theory of the firm, as understood by Mertens and Schumann.

The first example ("employee portal") by Mertens and Schumann shows that the consideration of different perspectives on the success of information systems can be quite useful. In the mentioned case an introduction of such an employee portal would obviously not be very successful from a pure cost perspective. However, this completely neglects the benefits of such an investment that are not measurable in monetary terms. A multidimensional analysis, also taking additional aspects such as user satisfaction and use as well as non-monetary individual and organizational benefits into account, would allow for a much more differentiated approach at this point. The second example highlights the complexity of the problem. In contrast to Mertens and Schumann, we consider the Deutsche Bahn ticket machines not only to make economic sense, but also see them as very practical, easy to use, and time-saving from user perspective. This makes clear that in our view the attempt at a universal mono-dimensional definition of IS success is not effective. Rather, the definition depends, among other things, on the objective of the analysis, the information system under investigation and its purpose, the objectives of the company, and the activities of the examined users. The actual measurement of information system success thus requires the situational definition of success. This applies, among others, also for the operationalization of "net benefits". The examiner can and must determine the dimensions of the investigation on his own again - if possible, taking existing research into account.

Mertens and Schumann criticize the IS success model of DeLone and McLean (2003). The substantive criticism can thus only refer to the relevant publications of these authors and does not relate to our contribution. As part of our literature review we conducted a preferably neutral analysis, without a single criticism of the examined contributions. In doing so, we also assumed an intact cumulative research tradition, where the important "old" research results are taken up in more recent works.

The word "existing" in the title refers to the scope of the search (period and media) of our literature analysis and is meant to indicate that the analysis refers to already published studies elsewhere. We cannot detect a logical error in this case.

\subsection{On Methodology}

With the increasing maturity of our discipline a wealth of literature on various topics has emerged. To obtain a comprehensive overview of the considered topic with finite effort, we conducted a deliberate and transparent selection of the sources. The most appropriate solution seemed to us to focus on the most prestigious journals and conference proceedings. It seems indisputable to us that the WIRTSCHAFTSINFORMATIK journal is the only high-class, internationally recognized, German-language journal of our discipline.

The impression repeatedly created by Mertens and Schumann that we have unilaterally regarded "U.S. research" is incorrect in our view since in the period and media analyzed there are actually researchers from different nations with relevant contributions who we analyzed without respect to their origin.

We still consider our argumentation concerning the selection of literature as relevant and useful. Surely even books are published which have been previously subjected to a formalized evaluation process. Unfortunately, this by no means applies to all books and cannot be easily determined for each individual book. We admit, however, that goodquality research for example of doctoral theses and professorial dissertations has not necessarily been published previously in journals or conference proceedings. Often this is done afterwards. Naturally we are also aware that submitted theses and dissertations are usually evaluated in terms of a rating or evaluation. After that, however, they are not necessarily revised in all cases. In our opinion, a multilevel, formalized review process similar to that of prestigious journals does not exist at all universities.

Our article focuses on recent research on information system success. One justification for the selected constraint is given in our work. As German-speaking researchers we deeply regret that relevant former German-language research has taken only a minor role in international, renowned science media. This finding regarding the publication behavior of some of the scientists within our research community should make us think. We are firmly convinced that we have to present our research results in the context of a globalization of science at international level as well and particularly.

The focus of our literature study is set on the established research stream "IS success research", which focuses on the individual factors of information system success. We deliberately chose this focus and clarified it by a - in our opinion very transparent description of the examination steps. In addition, there are - not only in the German-language literature also approaches considering information system effects at business and economic level. In the international research, these can be found, for example, in the research 
discourse on "IT business value", which, however, proceeds separately to the one investigated by our work and which was not the focus of our study.

In the quoted post by Braun et al. (2009) from the WI2009, the benefits management of IT projects has been analyzed with a completely different focus. We believe that the methodical approach also succeeds here. Moreover, this essay stands out - as opposed to some arbitrary choices in some other works - by its systematic and transparent selection of the literature.

\subsection{Further Work on the Economic Success of Information Processing}

We share the view of Mertens and Schumann that the German-language literature in the field of information system success has a lot to offer. The above mentioned examples demonstrate this adequately. Three of these works (Walter and Spitta 2004; Wehrmann and Zimmermann 2005; Wehrmann et al. 2006) from our chosen media are also included in the period analyzed in our literature study. If these works had also matched our focus of observation as regards content, the analysis of multi-dimensional approaches (in terms of effect models) to measure the success of information systems, we would have included them in our analysis. In our opinion, however, this is not the case.

\subsection{Outlook}

We would like to express our opinions regarding the raised "contemporary issues of BISE":

1. Regardless of whether justified or not, in our view it is a fact that knowledge transfer today is - especially in the international environment - primarily done through professional journals and conference papers. To obtain just a chance of acceptance in these media, scientists in turn need to refer to such sources.

2. In any kind of research, the respective strengths and weaknesses have to be properly taken into account. In our opinion, however, also in the international IS research some references to the theory of the firm exist. Here we would like to refer to the research on the "IT business value" again (e.g., Soh and Markus 1995; Melville et al. 2004; Kohli and Grover 2008). Moreover, the English language has established itself as a scientific language (but also generally as the "lingua franca”). Other scientists' lack of knowledge of the German language should not be criticized according to our view. Nor do we share the opinion that good German language skills are or should be required to achieve a reasonable overview of research findings at an international level. Similarly, we would not find it appropriate if we had to rely on publications in other widely used languages such as Chinese or Spanish, which are language that by no means all of us are able to speak. We have not the right to make overall depreciative statements regarding professional education, lacking practical relevance, and language skills of researchers from other nations, and we therefore reject those statements in principle.

3. The question of whether science provides truth is highly controversial in epistemology. This discussion goes beyond the boundaries of BISE and would lead too far at this point. We are of the opinion that "truth" or better scientific quality generally does not depend on the year of publication and language, but on the publication medium due to the different quality assurance. The aim of our study was to examine the latest literature from the considered field of research since previous research findings have been analyzed in previous literature studies - to which we refer to in our contribution. We did not impose any language restrictions. With one exception (most of the papers in the WIRTSCHAFTSINFORMATIK before 2009) all journals we identified as the leading journals are published in English. This again indicates that English is widespread in most of the research and is established as a scientific language.

\subsection{Conclusion}

We share the view of Mertens and Schumann that the German BISE research has much to offer and by no means has to hide from international research. Precisely for this reason we believe that the German BISE has to understand itself as part of international research and should publish according to this belief. Therefore, our suggestion to the authors of the letter to the editor is to publish an overview of the literature (also derived from the German-speaking area and older) on the economic efficiency of IT/IS in a top international journal. This would on the one hand contribute to a solid theoretical basis for our scientists who want to publish on an international level and therefore mainly have to rely on respective reputable sources. On the other hand, this knowledge would thus also be made available to the entire international research community in the current form.

Dipl.-Wirt.-Inf. Nils Urbach Prof. Dr. Stefan Smolnik Prof. Dr. Gerold Riempp Institute of Research on Information Systems (IRIS) European Business School (EBS) Oestrich-Winkel

\section{References}

to: Comments on the Contribution by Urbach et al. "The State of Research on Information Systems Success A Review of Existing Multidimensional Approaches"

Anselstetter R (1984) Betriebswirtschaftliche Nutzeffekte der Datenverarbeitung Anhaltspunkte für Kosten-Nutzen-Schätzungen. Springer, Heidelberg

Braun J, Ahlemann F, Riempp G (2009) Benefits management - a literature review and elements of a research agenda. In: Hansen HR, Karagiannis, D, Fill HG (eds) Business Services: Konzepte, Technologien, Anwendungen, 9. Internationale Tagung Wirtschaftsinformatik, Wien, pp 555-564

Brynjolfsson E (1993) The productivity paradox of information technology. Communications of the ACM 36(12):67-77

Brynjolfsson E, Hitt LM (2000) Beyond computation: information technology, organizational transformation and business performance. Journal of Economic Perspectives 14(4):23-48

DeLone WH, McLean ER (1992) Information systems success: the quest for the dependent variable. Information Systems Research 3(1):60-95

DeLone WH, McLean ER (2003) The DeLone and McLean model of information systems success: a ten-year update. Journal of Management Information Systems 19(4):9-30

Hamilton S, Chervany NL (1981) Evaluating information system effectiveness part I: comparing evaluation approaches. MIS Quarterly 5(3):55-69

Linß H (1995) Integrationsabhängige Nutzeffekte der Informationsverarbeitung. Deutscher Universitäts-Verlag, Wiesbaden

Mertens P, Anselstetter R Eckardt T, Nickel R (1982) Betriebswirtschaftliche Nutzen und Schäden der EDV. Zeitschrift für Betriebswirtschaft 52(2):135-154

Pilat D (2004) The ICT productivity paradox: insights from micro data. OECD Economic Studies, Paris 1:37-65 
Potthof I (1998a) Empirische Studien zum wirtschaftlichen Erfolg der Informationsverarbeitung. WIRTSCHAFSINFORMATIK 40(1):54-65

Potthof I (1998b) Kosten und Nutzen der Informationsverarbeitung - Analyse und Beurteilung von Investitionsentscheidungen. Deutscher Universitäts-Verlag, Wiesbaden

Schumann M (1993) Wirtschaftlichkeitsbeurteilung für IV-Systeme. WIRTSCHAFTSINFORMATIK 35(2):167-178

Urbach N, Smolnik S, Riempp G (2009a) Der Stand der Forschung zur Erfolgsmessung von Informationssystemen - Eine Analyse vorhandener mehrdimensionaler Ansätze. WIRTSCHAFTSINFORMATIK 51(4):363-375

Urbach N, Smolnik S, Riempp G (2009b) The state of research on information systems success - a review of existing multidimensional approaches. Business \& Information Systems Engineering 1(4):315-325

Walter SG, Spitta T (2004) Approaches to the ex-ante evaluation of investments into information systems. WIRTSCHAFTSINFORMATIK 46(3):171-180

Wehrmann A, Zimmermann S (2005) Integrierte Ex-ante-Rendite-/Risikobewertung von IT-Investitionen. WIRTSCHAFTSINFORMATIK 47(4):247-257

Wehrmann A, Heinrich B, Seifert F (2006) Quantitatives IT-Portfoliomanagement: Risiken von IT-Investitionen wertorientiert steuern. WIRTSCHAFTSINFORMATIK 48(4): 234-245

to: Statement of the Authors in Reply

to the Comments by P. Mertens and

M. Schumann on the Contribution

"The State of Research on Information

Systems Success - A Review of Existing

Multidimensional Approaches"

Braun J, Ahlemann F, Riempp G (2009) Benefits management - a literature review and elements of a research agenda. In: Hansen HR, Karagiannis D, Fill HG (eds) Business Services: Konzepte, Technologien, Anwendungen, 9. Internationale Tagung Wirtschaftsinformatik, Wien, pp 555-564

DeLone WH, McLean ER (2003) The DeLone and McLean Model of information systems success: a ten-year update. Journal of Management Information Systems 19(4):9-30
Kohli R, Grover V (2008) Business Value of IT: An essay on expanding research directions to keep up with the times. Journal of the AIS 9(1):23-39

Melville N, Kraemer K, Gurbaxani V (2004) Review: information technology and organizational performance: an integrative model of IT business value. MIS Quarterly 28(2):283-322

Soh C, Markus ML (1995) How IT creates business value: a process theory synthesis. In: Proceedings of the 16th International Conference on Information Systems (ICIS 1995). Amsterdam

Walter SG, Spitta T (2004) Approaches to the ex-ante evaluation of investments into information systems. WIRTSCHAFTSINFORMATIK 46(3):171-180

Wehrmann A, Zimmermann S (2005) Integrierte Ex-ante-Rendite-/Risikobewertung von IT-Investitionen. WIRTSCHAFTSINFORMATIK 47(4):247-257

Wehrmann A, Heinrich B, Seifert F (2006) Quantitatives IT-Portfoliomanagement: Risiken von IT-Investitionen wertorientiert steuern. WIRTSCHAFTSINFORMATIK 48(4): 234-245 


\section{Challenge, trust, a strong team. My know-how counts.}

Dr. Petra Stephan,

Allianz Deutschland AG, IT Manager

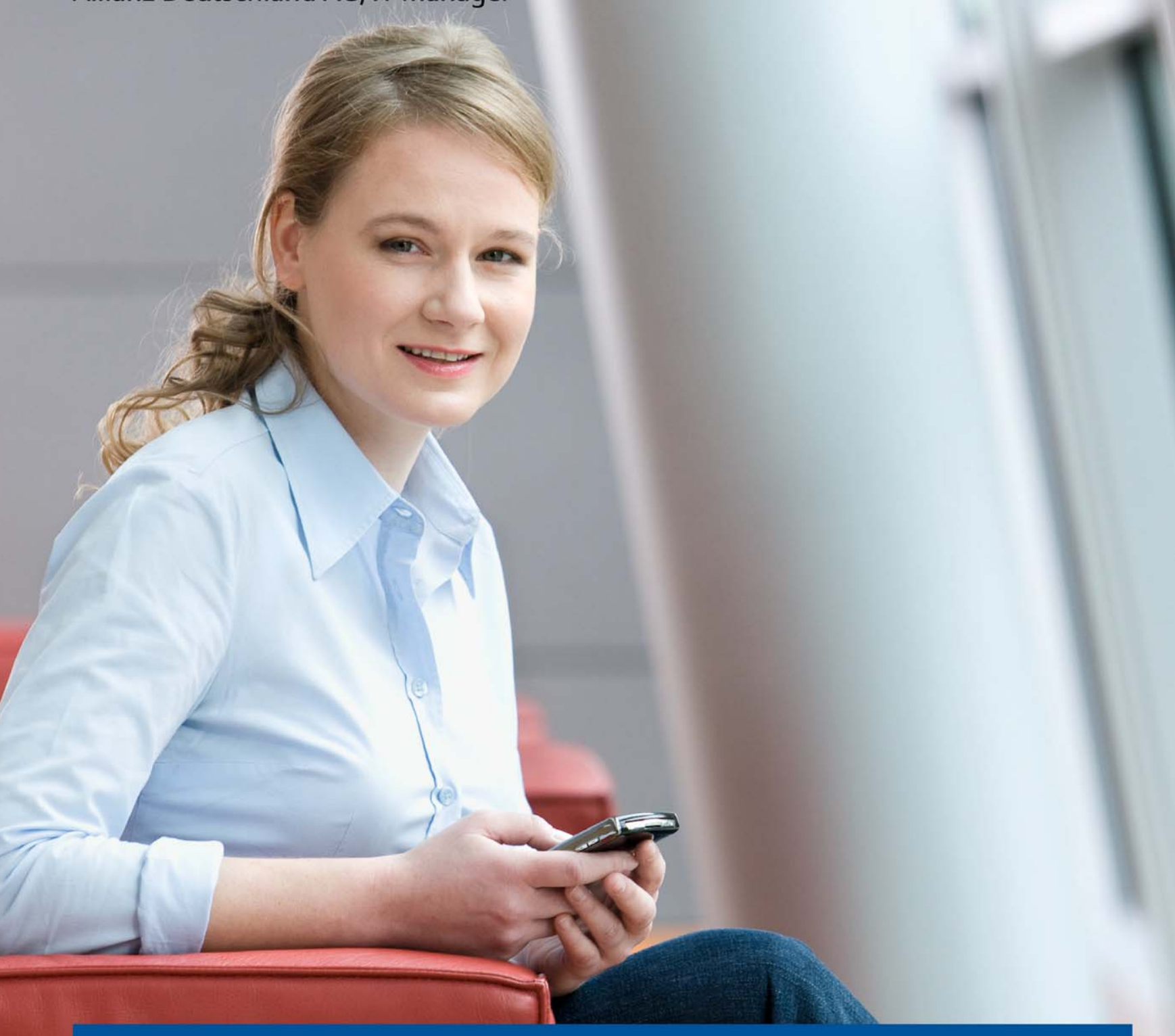

Allianz IT means maximum performance. Day by day, in many different countries of this world. We develop custom-made IT solutions in collaboration with both female and male colleagues. We rely on team spirit and trust.

What do you rely on?

www.perspektiven.allianz.de

\section{Allianz (III)}




\section{Gehen Sie den}

\section{Fragen der Zukunft} auf den Grund! 



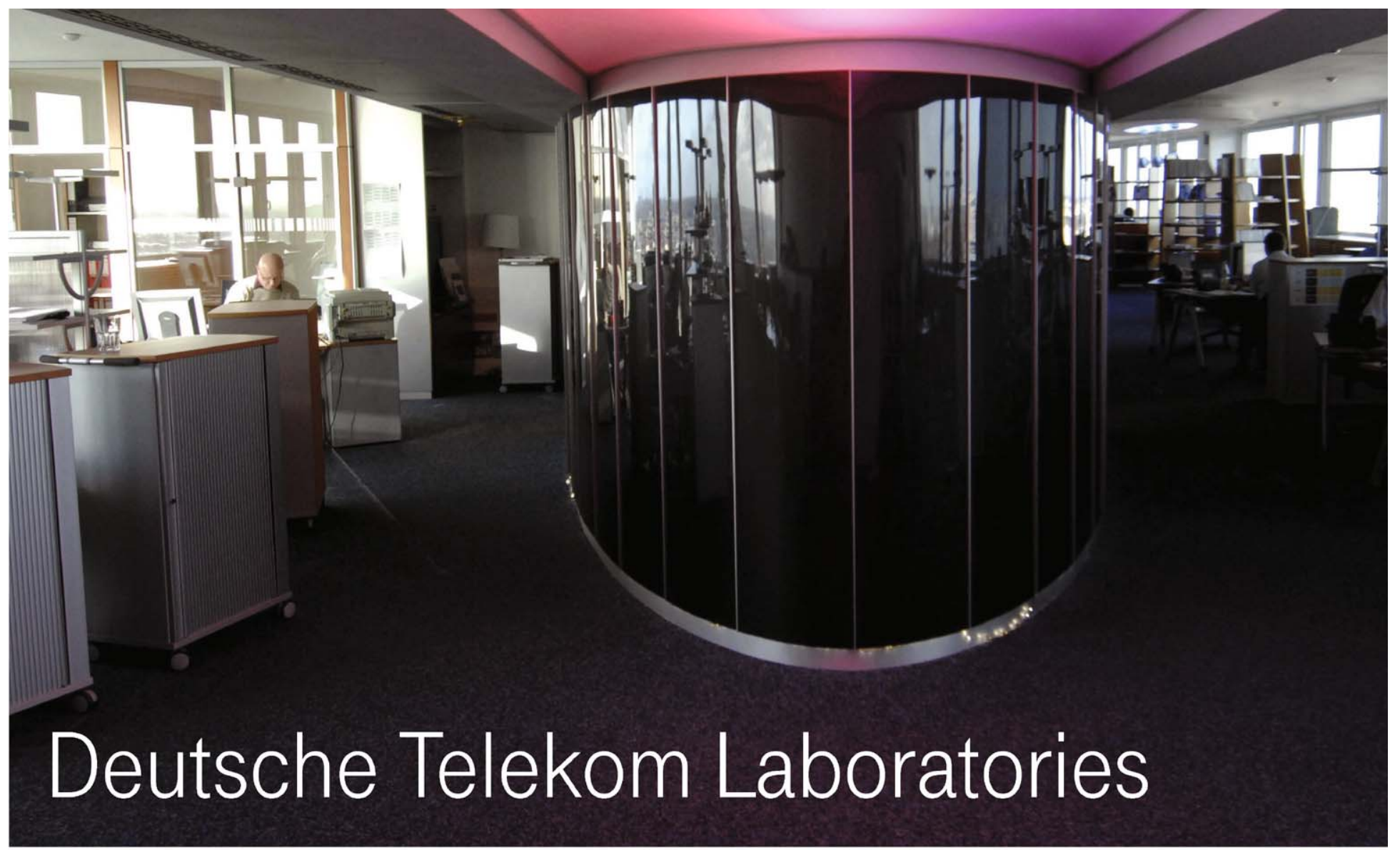

\section{We shape the future}

Deutsche Telekom Laboratories is Deutsche Telekom's research and development institute based in Berlin. It is simultaneously a scientific institute organized under private law and associated with the Technische Universität (TU) Berlin. At Deutsche Telekom Laboratories, scientists from across the globe work together with experts from the Group to develop new services and solutions for Deutsche Telekom's customers. Establishing new companies (spin-offs) is another method for making use of research output.

Cooperation with the TU Berlin, other universities and industry partners creates a bridge between business and science in order to turn ideas into marketable innovations as quickly as possible. As part of this, Deutsche Telekom Laboratories focuses on five fields of innovation ( $5 \mathrm{i}$ ):
- Intuitive Usability of services and devices

- Integrated Service Components

- Intelligent Access

- Infrastructure for IT and telecommunications

- Inherent Security

The business and information systems engineering offers useful interdisciplinary approaches for all these areas of innovation. Subject matter includes, for example, modeling, methods and tools for process innovations, agile architectures for information and communication technologies (ICT), technology-oriented management approaches and techno-economic assessments. The aim is to safeguard the economic sustainability of innovations for the Group.

Deutsche Telekom Laboratories is divided into two areas: The Innovation Development Laboratory focuses on market-centric research and development within a timeframe of up to three years.
The basic and technology research of the Strategic Research Laboratory has a long-term focus. Common goal: Deutsche Telekom Laboratories is looking to become one of the world's leading research and development institutions in the field of new ICT.

An institute was set up together with Ben-Gurion University in Beer Sheva, Israel, in 2006. Since 2008, Deutsche Telekom Laboratories has also been represented in Darmstadt. Another project office was opened in the Silicon Valley, United States, in January 2009.

\section{Contact:}

Deutsche Telekom Laboratories

Ernst-Reuter-Platz 7

10587 Berlin, Germany

E-mail:wi.laboratories@telekom.de www.laboratories.telekom.com

\section{Deutsche Telekom Laboratories}

An-Institut der Technischen Universität Berlin 


\section{We \\ proudly \\ present}

BUSINESS \& INFORMATION SYSTEMS ENGINEERING
Business \& Information Systems Engineering (BISE) is the new peer-reviewed scholarly e-journal for the entire techno-economically oriented community with a focus on design science-oriented research. It continues the 50 years' tradition of the journal WIRTSCHAFTSINFORMATIK by that all articles appear both in English and in German. Moreover, authors benefit from our double-blind, constructive, and rapid review process.

"I believe the time is opportune for the IS community to provide such outlets for design researchers. BISE, however, has some unique advantages for positioning itself as a desirable outlet for design science research."

\section{www.bise-journal.org}

